\title{
Dossiê/Dossier/Dosier
}

\section{Experimentalismo no Ensino Secundário nos anos 1950 e 1960}

\author{
Experimentalism in Secondary Education in the 1950s and 1960s
}

Experimentalismo en la Enseñanza Secundaria en los años 1950 y 1960:

\author{
ORGANIZAÇÃO \\ Norberto DALlabridA ${ }^{1}$ E DANIEL FERRAZ CHIOZZINI ${ }^{2}$
}

\section{Apresentação}

A partir dos anos 1950, o ensino secundário brasileiro conheceu diversas iniciativas que concorreram para a sua renovação. Um foco de reflexão pedagógica colocou-se no Centro Brasileiro de Pesquisas Educacionais (CBPE), criado em 1955, a partir da parceria estabelecida por Anísio Teixeira, diretor do INEP, e a UNESCO. Embora de forma não prioritária, no INEP/CBPE o ensino secundário foi objeto de pesquisas tanto em nível nacional como nos seus centros regionais de pesquisa. Nesse órgão educacional ganhou destaque as análises de Jayme Abreu, técnico muito próximo a Anísio Teixeira, que coordenou a Campanha de Inquéritos e Levantamentos do Ensino Médio e Elementar e atuou no INEP até a década de 1960. Sobre o ensino secundário, realizou pesquisas, representou o Brasil em congressos internacionais e publicou diversos trabalhos em forma de artigos científicos e de livro. De outra parte, em 1953, a Diretoria do Ensino Secundário do MEC criou a Campanha de Aperfeiçoamento e Difusão do Ensino Secundário (CADES) que tinha como intuito qualificar e certificar os professores leigos nesse nível de ensino por meio de cursos realizados nas férias. Para incrementar a sua ação em nível nacional, quatro anos depois, a CADES instituiu a revista "Escola Secundária", tendo uma

\footnotetext{
${ }^{1}$ Doutor em História Social pela Universidade de São Paulo, com estágios de pós-doutorado concluídos na Université Rene Descartes - Paris V e na Universidad de Alcalá de Henares (Espanha). Professor de História da Educação e pesquisador da Universidade do Estado de Santa Catarina. Bolsista de Produtividade em Pesquisa do CNPq. E-mail: norbertodallabrida@hotmail.com

${ }^{2}$ Doutor em Educação pela Universidade Estadual de Campinas, com estágio de pós-doutorado concluído na Pontifícia Universidade Católica de São Paulo. Professor do Programa de Estudos Pós-Graduados em Educação: História, Política, Sociedade da Pontifícia Universidade Católica de São Paulo. E-mail: danielchiozzini@yahoo.com.br
} 
linha editorial voltada para as questões didáticas, que publicava relatos de experiências de diferentes disciplinas dos cursos ginasial e colegial (DALLABRIDA e SOUZA, 2014).

A renovação mais contundente nesse nível de escolarização foi colocada em marcha pela Diretoria do Ensino Secundário (DESe) do MEC na gestão de Gildásio Amado. Em meados de 1958, a DESE viabilizou a oficialização das "Instruções sobre a natureza e a organização das classes experimentais", que autorizavam, a partir do ano letivo seguinte, a instalação de classes experimentais no ensino secundário, preferencialmente no curso ginasial. Essa legislação prescrevia o desenvolvimento das aptidões individuais dos alunos, que se efetivava na limitação de até trinta alunos por sala de aula e na possibilidade de os discentes optarem por disciplinas e atividades educativas. E também estipulava exigência em relação ao corpo docente, que deveria ter reuniões regulares, sendo agrupado por classes, particularmente para viabilizar a integração de “disciplinas-saber". Desta forma, a partir de 1959, começaram a ser implantadas, em um punhado de colégios - especialmente no curso ginasial, o primeiro ciclo do ensino secundário - as classes secundárias experimentais, que construíram uma marcante renovação no ensino secundário brasileiro. Em 1962, quando fechou o ciclo de quatro anos do curso ginasial, havia no Brasil 46 estabelecimentos de ensino secundário que tinham feito ensaios renovadores, sendo que a maioria se localizava nos estados de São Paulo e do Rio de Janeiro (Cunha; Abreu, 1963).

Nesse pequeno conjunto de experiências educacionais renovadoras, a classe experimental secundária que ganhou maior relevo foi aquela realizada no Instituto Estadual Narciso Pieroni do município paulista de Socorro, coordenada pelas professoras Lygia Furquim Sim, Olga Bechara e Maria Nilce Mascelani. As chamadas Classes de Socorro chamaram a atenção do Secretário Estadual de Educação do Estado de São Paulo, Luciano de Carvalho, inspirando um novo projeto educacional: os ginásios vocacionais. Para tanto, por meio da Lei 6.052, de 3 de fevereiro de 1961, foi criado o Serviço de Orientação Vocacional (SEV), que estruturou o ensino industrial no Estado de São Paulo. No início desse ano, Maria Nilde Mascelani assumiu a coordenação do SEV e iniciou a implantação dos ginásios vocacionais, que tiveram como referência as classes secundárias experimentais, mas intensificaram o engajamento político. A experiência dos ginásios vocacionais desenvolveu-se na década de 1960, sendo terminada, de forma autoritária, após o endurecimento do regime militar colocado em marcha pelo AI-5 (Chiozzini, 2014). Desta forma, nos anos 1950 e 1960, as classes secundárias experimentais e os ginásios vocacionais se converteram nos principais ensaios escolares de renovação do ensino secundário.

Nesta direção, o presente dossiê procura refletir sobre experiências educativas no ensino secundário durante as décadas de 1950 e 1960 que tiveram como clave o experimentalismo pedagógico no Brasil e no Uruguai. O texto “'Nueva Educación' y enseñanza secundaria en el Uruguay (1939-1963)”, do historiador Antonio Romano, reflete sobre transformações significativas no ensino secundário uruguaio implementadas a partir da Segunda Guerra Mundial, especialmente a partir da apropriação das classes nouvelles, dando destaque para o papel das revistas na circulação de ideias pedagógicas. De outra 
parte, esse trabalho reflete sobre o Plano de Estudos de 1963, proposto pelo Diretor Geral do Ensino Secundário, professor Alberto Rodriguez, que introduziu uma nova estrutura no ensino secundário, prevendo cinco anos de formação geral e integral e um ano de caráter pré-profissional. A partir dessa nova configuração escolar, foram implantados, na capital e no interior do nosso país vizinho, os chamados "liceus de ensaio", marcados pelo experimentalismo pedagógico. O artigo de Antonio Romano abre caminho para um diálogo historiográfico sobre o ensino secundário entre os países do Mercosul e/ou da América Latina.

Os textos sobre a renovação do ensino secundário no nosso país obedecem, grosso modo, um critério cronológico. Assim, o trabalho de Letícia Vieira e Norberto Dallabrida colocam o foco sobre o pioneirismo de Luís Contier na apropriação das classes nouvelles no Brasil, que começou a quebrar o rígido ensino secundário formatado pela Reforma Capanema que ainda vigorava após o Estado Novo. Aborda o estágio do professor Contier no Centre International d'Études Pedagogiques (CIEP), no início dos anos 1950, e os primeiros usos que ele realizou das classes nouvelles francesas no Instituto de Educação Alberto Conte, localizado em São Paulo. De outra parte, explora o processo da oficialização das classes secundárias experimentais pelo Ministério da Educação, em meados de 1958, bem como a implantação das mesmas a partir do início do ano seguinte. $\mathrm{O}$ artigo de Sérgio Roberto Chaves Júnior lê as chamadas classes integrais - nome dado às classes secundárias experimentais - no Colégio Estadual do Paraná, que se apropriaram especialmente do Método por Unidades Didáticas desenvolvido no Colégio de Nova Friburgo. Essa experiência renovadora é constatada em vários aspectos, entre os quais são destacados a educação integral, a integração curricular - particularmente das disciplinas História e Geografia - e as atividades extraclasse como o clubismo.

No texto "Educação renovada no Estado de São Paulo: a experiência pioneira do ensino continuado e as práticas escolares do Experimental da Lapa (1961-1971)", Carlos Eduardo Bizzocchi analisa a cultura escolar de corte escolanovista praticada em uma escola que ficou conhecida como Grupo Escolar - Ginásio Experimental Dr. Edmundo de Carvalho, popularmente chamado Experimental da Lapa. Esse trabalho histórico foi realizado sobremaneira a partir de fontes estimulantes como os relatórios das unidades da escola e os chamados "cadernos" - onze publicações que relatam e avaliam a prática educativa no Experimental da Lapa. Maria Odete Pereira Mundim, Carlos Henrique de Carvalho e Décio Gatti Júnior trazem à baila os encaminhamentos de criação e o funcionamento da Escola Vocacional de Aprendizagem Industrial de Uberlândia, localizada no Estado de Minas Gerais, especialmente na década de 1960. É importante frisar que esse colégio técnico foi pautado, a partir de 1962, pelas prescrições da Lei $\mathrm{n}^{\mathrm{o}}$ 4.024, de 20 de dezembro de 1961, que fixou as Diretrizes e Base da Educação Nacional, unificando formalmente os cursos secundário e técnico, criando o ensino médio e permitindo a flexibilização curricular por meio do oferecimento de "disciplinas-saber" escolhidas por cada escola. 
Este dossiê é coroado com um trabalho que procura cotejar as relações entre as classes secundárias experimentais e os ginásios vocacionais assinado por Daniel Ferraz Chiozzini e Sandra Machado Lunardi Marques. As aproximações entre esses dois ensaios educativos de corte inovador confluem para uma discussão sobre o experimentalismo e para a educadora Maria Nilde Mascelani, que atuou na Classes de Socorro e coordenou o projeto dos ginásios vocacionas. No entanto, esse texto produzido a quatro mãos também explora, de forma instigante, as diferenças entre as classes experimentais dos anos $1950 \mathrm{e}$ os ginásios vocacionais da década de 1960. Enfim, esse exercício comparativo é muito salutar e pode estimular novas investigações em torno da renovação do ensino secundário.

\section{Referências}

CHIOZZINI, Daniel Ferraz. Memória e História da Inovação Educacional no Brasil: o caso dos Ginásios Vocacionais (1961/1970). Curitiba: Appris, 2014.

CUNHA, Nádia; ABREU, Jayme. Classes Secundárias Experimentais: balanço de uma experiência. Revista Brasileira de Estudos Pedagógicos, Rio de Janeiro. v. XL, n. 91, p.90-151, 1963.

DALLABRIDA, Norberto; SOUZA, Rosa Fátima de. "O todo-poderoso império do meio": transformações no ensino secundário entre a Reforma Francisco Campos e a primeira LDBEN (à guisa de apresentação). In: Entre o ginásio de elite e o colégio popular: estudos sobre o ensino secundário no Brasil (1931-1961). Uberlândia, MG: EDUFU, 2014. p.11-30. 